\title{
STRATEGI PENGEMBANGAN KUALITAS PELAYANAN UNTUK MEMENUHI KEINGINAN KONSUMEN PADA BENGKEL WIJAYA TOYOTA
}

\author{
Anggit Suryopratomo \\ Fakultas Ekonomi Universitas Bandung Raya \\ Jl. Banten 11 Bandung \\ Email: suryopratomo.anggit@gmail.com
}

\begin{abstract}
This study addresses the complex problems in taking a decision to achieve corporate objectives, to improve the quality of consumer care services, as well as care services in accordance with the wishes of the customer in Workshop Wijaya Toyota (PT Wijaya Motor Lestari) in partnership with PT Astra International Tbk. This research is descriptive, assigning a sample of 100 customers. Data were processed in the qualitative methods using Quality Function Deployment and the result was displayed in a matrix House of Quality. The results show that strategies the workshop Wijaya Toyota applies to improving the quality of services are: the waiting room and toilet cleanliness, promoting warranty repair workshop, ensuring the accuracy of completion time of maintenance, speed of completion of the work, maintenance appropriate to their complaints, garage attendant explanation of maintenance, stock availability of original spare parts, direct workshop personnel explanation at the time of submission, garage attendant explanation upon delivery, transparent overall cost to be paid, reasonableness price of original parts, friendliness and courtesy officer spare parts, and workshop personnel direct contact.
\end{abstract}

Keywords: voice of customer, technical characteristic, QFD, HOQ

\section{PENDAHULUAN}

Industri otomotif di Indonesia diawali dengan perakitan oleh General Motor di Tanjung Priok pada tahun 1927, sedang NV Indonesia Service Company merupakan pabrik perakitan kedua yang didirikan pada tahun 1954. Pada saat itu industri otomotif di Indonesia sebagian besar merakit mobil-mobil buatan AS dan Eropa.

Sejalan dengan gejolak politik dan kemerosotan ekonomi nasional sampai dengan akhir dasawarsa 1960-an, perkembangan industri otomotif seolah-olah ikut tenggelam. Pada tahun 1970-an industri otomotif bangkit kembali, ditandai dengan diproduksi dan dipasarkannya mobil buatan Jepang. Pada pertengahan tahun 1969 PT Astra Group ditunjuk sebagai agen tunggal pemegang merek (ATPM) dari mobil Toyota, sedangkan Daihatsu pada tahun 1973. Selanjutnya perusahaan ini juga mengageni merek BMW, Peugeut, Isuzu, dan Nissan Diesel. Sementara itu, pada tahun 1971 Krama Yudha mengageni merek Mitsubishi yang sempat beberapa tahun mendominasi pangsa pasar mobil di Indonesia. Pada tahun 1980-an kelompok Salim terjun ke bisnis otomotif dengan mengageni merek: Suzuki, Hino, Mazda, Volvo, dan kemudian Nissan. Ketiga kelompok tersebut (Astra, Krama Yudha, dan Salim) saat ini menguasai kurang lebih 85\% pasar mobil di Indonesia. Disamping ketiga kelompok tersebut masih terdapat beberapa ATPM yang mengageni merek Honda, Mercedez Benz, Ford, Opel, Chevrolet, Citroen, dan sejak pertengahan tahun 1995 Hyundai dan Daewoo dari Korea Selatan ikut meramaikan pasar mobil Indonesia. Pada sekitar tahun 
2000 juga muncul merek KIA yang diageni oleh KMI dan kemungkinan akan disusul pula oleh merek-merek lainnya.

Semakin ketatnya persaingan dalam bisnis otomotif dewasa ini, telah memaksa perusahaan pemegang merek ATPM untuk terus mencari terobosan-terobosan baru dalam bidang pelayanan (service) kepada pembelinya. Memberikan pelayanan terbaik merupakan kiat suatu perusahaan untuk memenangkan persaingan yang semakin ketat saat ini. (wikipedia, 2012)

PT Toyota-Astra Motor diresmikan pada tanggal 12 April 1971. Peranan TAM semula hanya sebagai importir kendaraan Toyota, namun setahun kemudian sudah berfungsi sebagai distributor. Dalam mendukung penjualan dan layanan purna jual, TAM dibantu oleh 5 Dealer Utama yang membawahi dealer-dealer yang tersebar di seluruh Indonesia. Hingga bulan Desember 2005 telah terdapat 181 outlet dan 101 bengkel resmi.

Dalam menghadapi persaingan yang semakin tajam di pasaran mobil saat ini. TAM terus berupaya meningkatkan pelayanan pada pelanggannya melalui hubungan kemitraan. Pelayanan terbaik kepada pelanggan menjadi perhatian utama sejak pra pembelian, saat pembelian maupun setelah terjadinya jual beli mobil melalui pelayanan purna jual. Program pelayanan purna jual menggunakan falsafah 3s (Sale, Service and Spare Parts). Dengan memberikan pelayanan terbaik kepada pelanggan diharapkan dapat terus membina dan mempertahankan citra produk yang dijual, sehingga volume penjualan terus dapat ditingkatkan.

Dalam pelaksanaan program pelayanan purna jual peranan bengkel cukup besar. Tersedianya bengkel dengan peralatan lengkap dan canggih serta tenaga teknisi yang terampil merupakan penunjang bagi unit penjualan. Bengkel Wijaya Toyota (PT Wijaya Motor Lestari) merupakan jaringan jasa penjualan, perawatan, perbaikan dan penyediaan suku cadang Toyota yang manajemennya ditangani penuh oleh PT Astra International Tbk.

Wijaya Toyota adalah main dealer Toyota di Bandung yang berdiri sejak 08 Oktober 1994. Dalam aktivitas bisnisnya, Wijaya Toyota berhubungan dengan PT Toyota Astra Motor yang menjadi Agen Tunggal Pemegang Merek (ATPM) Toyota. Wijaya Toyota adalah salah satu dealer resmi Toyota di wilayah Jawa Barat. Bengkel Wijaya Toyota Jl. Ahmad Yani, Bandung merupakan salah satu bengkel yang telah lama berdiri dan memiliki banyak pelanggan. Dengan cabang bengkel yang tidak banyak dibanding Auto2000, Wijaya Toyota tetap bisa mengelola bisnis dengan baik.

Dari data yang diperoleh mengenai jumlah kunjungan konsumen Wijaya Toyota belum menunjukkan adanya peningkatan kuantitas kunjungan konsumen yang signifikan pada periode tahun 2011-2012. Bahkan jumlah kunjungan pada bulan September 2012 mengalami penurunan dibandingkan bulan Agustus 2012. Hal ini menarik untuk diteliti, karena untuk bertahan di dalam persaingan yang ketat ini sangat tidak mudah. Wijaya Toyota harus mampu memberikan pelayanan yang lebih dari harapan pelanggan mengingat banyak pesaing dalam kompetisi jasa bengkel ini. (Tabel 1).

Bengkel Wijaya Toyota menawarkan pelayanan yang nyaman untuk pelanggannya, ketepatan waktu selesai service kendaraan kepada konsumen, Discount biaya jasa jika booking terlebih dahulu, serta kerjasama dengan perusahaan lain untuk memberikan nilai tambah. Kendala di bengkel Wijaya Toyota adalah masih belum terpenuhinya seluruh keinginan pelanggan setianya. Hal ini terungkap berdasarkan wawancara dengan salah satu pelanggan bengkel Wijaya Toyota yang menyatakan 
bahwa jumlah pelanggan yang banyak dari bengkel Wijaya Toyota menyebabkan waktu menunggu service kendaraan menjadi lama serta tidak mencukupinya ruang tunggu pelanggan bengkel, tidak adanya pemberitahuan dari petugas bilamana kendaraan pelanggan telah selesai di service, masih seringnya terjadi ketidaksesuaian mengenai waktu penyelesaian perbaikan, kurangnya penjelasan petugas bengkel tentang perbaikan secara keseluruhan yang telah dilaksanakan serta perbaikan yang telah dilakukan oleh petugas bengkel dirasakan masih belum sesuai dengan keluhan, selain itu pelanggan bengkel Wijaya Toyota harus menunggu lama untuk spare part yang harganya relatif tinggi misalnya lampu utama depan bohlam kendaraan Toyota vios.

Tabel 1. Jumlah Pelanggan Service Bengkel Wijaya Toyota 2011 - 2012

\begin{tabular}{|c|c|c|}
\hline \multicolumn{2}{|c|}{ Jumlah Kunjungan Bengkel Wijaya Toyota Periode Tahun 2011-2012 } \\
\hline Bulan & Tahun & Jumlah Pelanggan \\
\hline September & 2011 & 941 \\
\hline Oktober & 2011 & 989 \\
\hline November & 2011 & 1029 \\
\hline Desember & 2011 & 1021 \\
\hline Januari & 2012 & 999 \\
\hline Februari & 2012 & 1026 \\
\hline Maret & 2012 & 970 \\
\hline April & 2012 & 932 \\
\hline Mei & 2012 & 937 \\
\hline Juni & 2012 & 1070 \\
\hline Juli & 2012 & 1147 \\
\hline Agustus & 2012 & 910 \\
\hline September & 2012 & 12791 \\
\hline
\end{tabular}

Pada saat ini bengkel Wijaya Toyota masih melakukan usaha-usaha guna memecahkan kendala tersebut, seperti service kendaraan di rumah konsumen dan untuk akhir pekan bengkel Wijaya Toyota menyediakan jasa service hari libur dan minggu yaitu melayani jasa service di hari libur nasional dan libur hari minggu sampai pukul 12:00. Hal ini tetap membutuhkan concern khusus sehingga kepuasan pelanggan tetap menjadi prioritas perusahaan.

Pesaing di ranah jasa bengkel ini selain memiliki citra yang baik, juga memiliki daya saing yang tinggi sehingga merupakan suatu tantangan yang besar bagi bengkel Wijaya Toyota untuk tetap bertahan dan memenangkan persaingan. Maka strategi yang harus dipilih dan pelayanan yang diberikan harus memiliki nilai lebih dibanding pesaingnya. Bengkel Wijaya Toyota memiliki cabang yang cukup strategis di kota Bandung ini yaitu di Dago. bengkel Wijaya Toyota ingin memenangkan persaingan di segmen service kendaraan Toyota. Namun banyaknya bengkel Toyota di kota Bandung menyebabkan persaingan bengkel Toyota ini semakin ketat, hal ini memicu bengkel Wijaya Toyota melakukan perbaikan pelayanan untuk mempertahankan kesetiaan pelanggannya.

Untuk meningkatkan kinerja pelayanan service kendaraan kepada konsumen, dimana hal ini akan menentukan kualitas layanan bengkel Wijaya Toyota, perlu dilaksanakan prosedur evaluasi (penilaian) kualitas yang selama ini belum pernah dilakukan di Wijaya Toyota, dengan menggunakan model House of Quality (HOQ) dan Gap Analysis yang melibatkan konsumen sebagai subjek evaluasi. HOQ dapat digunakan sebagai alat komunikasi agar seluruh karyawan di setiap level organisasi mengetahui secara pasti posisi technical characteristics terhadap voice of customer. 
Sehingga hal tersebut dapat memotivasi seluruh karyawan untuk melakukan perbaikanperbaikan agar kinerja Wijaya Toyota semakin membaik. Hasil penilaian kualitas dengan HOQ tersebut kemudian dikorelasikan dengan hasil penelitian menggunakan model GAP Analysis untuk dapat menemukan penyebab terjadinya kesenjangan antara persepsi pelanggan dengan pihak manajemen Wijaya Toyota. Mengkombinasikan kedua model tersebut diharapkan dapat ditemukan strategi, untuk meningkatkan kepuasan pelanggan Wijaya Toyota melalui pemberdayaan sistem kerja dan SDM bengkel Wijaya Toyota, yang diselaraskan dengan kebutuhan dan keinginan pelanggan.

Berdasarkan uraian di atas maka dilakukan penelitian dengan judul "Strategi Pengembangan Kualitas Pelayanan Dalam Rangka Memenuhi Keinginan Konsumen Pada bengkel Wijaya Toyota".

\section{Identifikasi dan Rumusan Masalah}

Semakin banyaknya jumlah merek mobil yang beredar di Indonesia dan di lain pihak semakin banyak pula bengkel-bengkel tidak resmi yang cukup baik, maka sebagai dampaknya dapat diduga akan terjadi persaingan yang sangat ketat. Oleh karena itu memberikan pelayanan terbaik merupakan suatu upaya ATPM dalam memenuhi keinginan pelanggan.

Penjualan Toyota saat ini sangat berkembang pesat dikarenakan konsumen diberikan kemudahan fasilitas dalam pelayanan purna jual nya, dapat dilihat dari banyaknya bengkel-bengkel ATPM Toyota baru di kota Bandung. Hal ini merupakan tantangan bagi bengkel Wijaya Toyota untuk tetap mempertahankan pelanggannya dikarenakan dengan bermunculan bengkel Toyota yang baru dan siap "mencuri" pelanggan dengan peluang yang ada.

PT Wijaya Lestari memulai bisnis bengkel khusus kendaraan Toyota di tahun 1994 dengan layanan standard perbaikan kendaraan Toyota. Di tengah banyak tumbuhnya pesaing bengkel ATPM Toyota baru di kota Bandung, perusahaan terus berusaha dan bertahan dalam bisnis otomotif ini. komitmen perusahaan untuk meningkatan pelayanan dan jaminan kepuasan pelanggan menjadi daya tarik sendiri bagi peneliti.

Fokus permasalahan yang akan diangkat dalam penelitian ini dituangkan dalam rumusan masalah berikut :

1. Bagaimana Voice of Customer atas pelayanan bengkel Wijaya Toyota saat ini

2. Technical characteristic apa yang bisa disediakan bengkel Wijaya Toyota untuk memenuhi Voice of Customer bengkel Wijaya Toyota

3. Bagaimana HOQ bengkel Wijaya Toyota

4. Strategi apa yang dapat dikembangkan untuk meningkatkan pelayanan pelanggan bengkel Wijaya Toyota

\section{METODE PENELITIAN \\ Rancangan Penelitian}

Metode penelitian yang digunakan adalah deskriptif. Penelitian deskriptif menurut Sugiyono (2004:11) merupakan penelitian yang digunakan untuk mengetahui nilai variabel mandiri, baik satu variabel atau lebih (independent) tanpa membuat perbandingan atau menghubungkan dengan variabel yang lain. Atas dasar ini, penelitian deskriptif sebenarnya hanya ditujukan untuk memperoleh gambaran atas suatu kejadian tanpa harus menyelidiki lebih lanjut tentang sebab dan hubungan yang terjadi antar variabel dalam kejadian yang diteliti.Dalam penelitian deskriptif ini, peneliti 
menggunakan strategi kuantitatif (misalnya, teknik kuesioner dan observasi) untuk mengumpulkan data (misalnya, berupa skor) atau informasi tentang ciri-ciri orang, kelompok orang, program, atau sesuatu yang berkaitan dengan pendidikan.

\section{Sumber dan Cara Penentuan Data}

\section{a. Data Primer}

Data primer merupakan data yang diambil secara langsung. Data ini diperoleh melalui observasi, kuesioner dan wawancara. Data primer yang didapat dari observasi digunakan untuk mencari gejala permasalahan atau isu yang muncul berkaitan dengan Service Quality di bengkel Wijaya Toyota. Data primer yang didapat melalui instrument kuesioner digunakan untuk mengidentifikasi apa yang menjadi prioritas kebutuhan pelanggan. Sedangkan melalui wawancara, penulis mendapatkan informasi mengenai apa yang telah perusahaan lakukan saat ini dalam usaha mencapai kepuasan pelanggan serta mendapatkan informasi mengenai apa yang menjadi keluhan pelanggan terhadap kinerja bengkel Wijaya Toyota selama ini.

b. Data Sekunder

Data sekunder didapatkan dari berbagai literature guna mendukung hasil penelitian yang bersumber dari bahan bacaan mengenai PT. Wijaya Toyota.

\section{Populasi dan Sampel}

Yang menjadi populasi pada penelitian ini adalah pelanggan bengkel Wijaya Toyota Ahmad Yani yang menjadi pelanggan PT. Wijaya Toyota.

Besar sampel ditentukan dengan menggunakan rumus Slovin :

$$
n=\frac{N}{1+N e^{z}}
$$

Keterangan:

$$
\begin{aligned}
& \mathrm{n}=\text { Ukuran Sampel } \\
& \mathrm{N}=\text { Ukuran populasi } \\
& \mathrm{e}=\text { Taraf ketelitian }(10 \%)
\end{aligned}
$$
berikut:

Berdasarkan rumus tersebut, maka dapat dihitung besarnya sampel sebagai

$$
\begin{aligned}
& n=\frac{12791}{1+(12791)(0.1)^{2}} \\
& n=99,224 \approx 99 \text { Pelanggan }
\end{aligned}
$$

Berdasarkan jumlah perhitungan, maka sampel yang diambil adalah sebanyak 99 pelanggan, dibulatkan menjadi 100 pelanggan.

\section{Teknik Analisis Data}

Adapun analisis penentuan prioritas peningkatan kualitas pelayanan menggunakan teknik Quality Function Deployment. Dari analisis ini kita dapat mengetahui priotitas peningkatan kualitas pelayanan bengkel Wijaya Toyota. Ada 7 tahap yang harus ditempuh dalam membentuk maktriks QFD (sering disebut dengan House of Quality), yaitu: 
1. Mengidentifikasi kebutuhan konsumen terhadap jasa bengkel Toyota.

2. Identifikasi karakteristik teknis.

3. Menentukan hubungan antara kebutuhan konsumen dan karakteristik teknis.

4. Membentuk matriks korelasi antara masing-masing karakteristik teknis.

5. Menghitung prioritas karateristik jasa.

6. Menentukan target karakteristik teknis.

7. Menentukan arah perbaikan (Benchmark yang dipilih bengkel Toyota Auto2000 Cibiru).

\section{Bagan Alir}

Bagan alir untuk permasalahan ini mengikuti tahap-tahap seperti yang ditunjukan dalam bagan berikut ini:

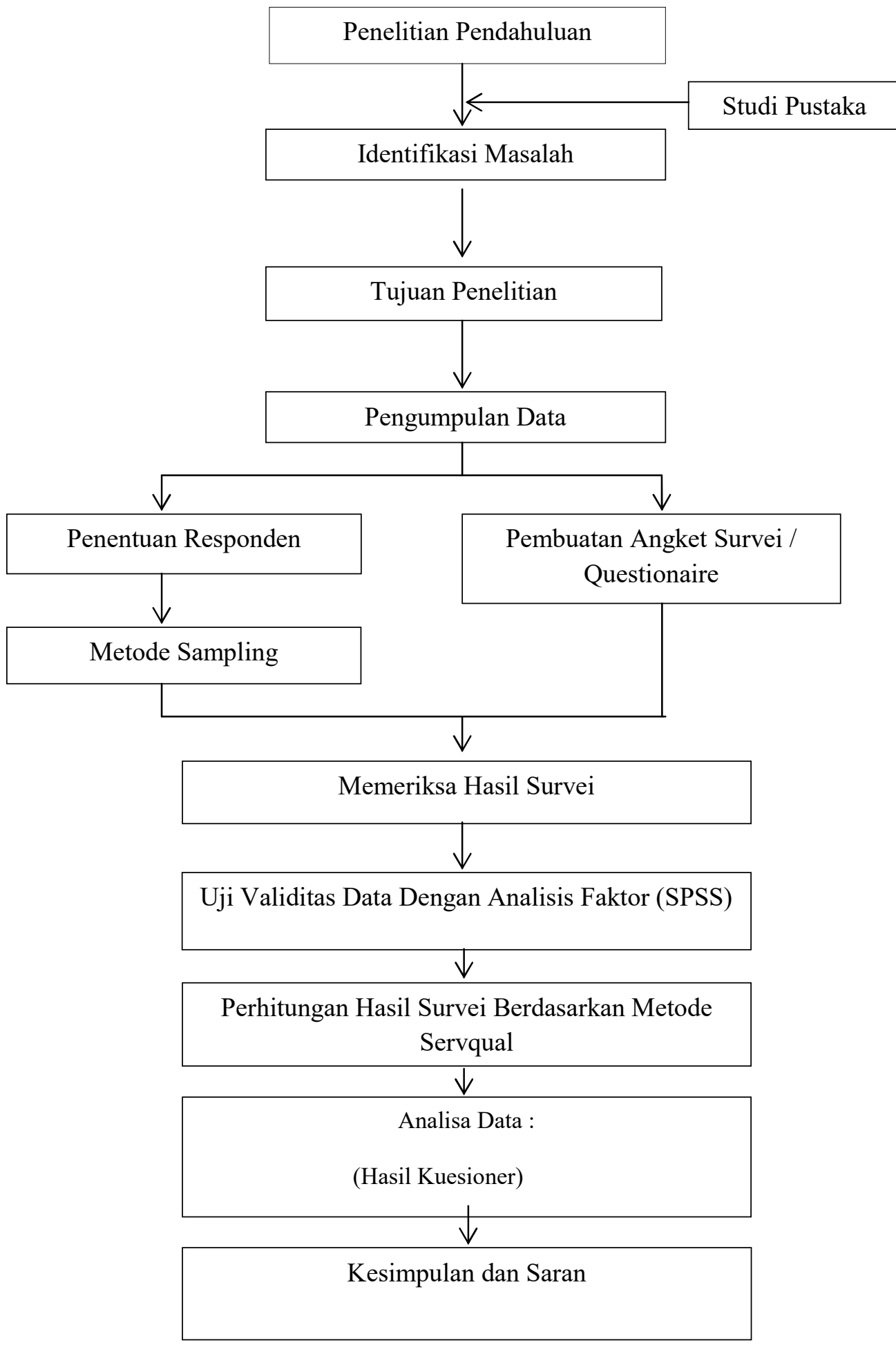




\section{HASIL DAN PEMBAHASAN}

\section{Gap Analysis}

Untuk melihat gap antara persepsi dan harapan pelanggan atas pelayanan yang diberikan, maka dilakukan perhitungan ServQual berdasarkan selisih antara persepsi dan harapan. Dari peritungan itu diperoleh atribut-atribut yang memiliki nilai negatif yaitu atribut-atribut yang memiliki potensi konflik kepentingan pihak pelanggan dalam memenuhi kebutuhannya. Hasil perhitungan dapat dilihat dalam tabel 2 berikut:

Tabel 2. Hasil analisis gap angket

\begin{tabular}{|c|c|c|c|c|}
\hline No. & Atribut Pelayanan & Persepsi & Harapan & Nilai CI \\
\hline 1 & Fasilitas gedung bengkel Wijaya Toyota & 3.26 & 3.45 & -0.19 \\
\hline 2 & Tersedianya tempat parker & 2.50 & 3.67 & -1.17 \\
\hline 3 & Kondisi ruangan bengkel & 3.40 & 3.65 & -0.25 \\
\hline 4 & Fasilitas dan kebersihan ruang tunggu & 2.96 & 3.84 & -0.88 \\
\hline 5 & $\begin{array}{l}\text { Sikap petugas terhadap perbaikan yang masih dalam garansi } \\
\text { perbaikan bengkel }\end{array}$ & 3.15 & 3.82 & -0.67 \\
\hline 6 & $\begin{array}{l}\text { Ketepatan janji petugas mengenai waktu penyelesaian } \\
\text { perawatan/perbaikan }\end{array}$ & 1.84 & 3.77 & -1.93 \\
\hline 7 & Kecepatan penyelesaian pekerjaan & 1.66 & 3.75 & -2.09 \\
\hline 8 & $\begin{array}{l}\text { Perawatan/perbaikan yang tepat sesuai dengan } \\
\text { permintaan/keluhan }\end{array}$ & 2.74 & 3.83 & -1.09 \\
\hline 9 & Kemudahan membuat janji & 2.25 & 3.20 & -0.95 \\
\hline 10 & Penjelasan petugas bengkel tentang perawatan/perbaikan & 2.92 & 3.78 & -0.86 \\
\hline 11 & Menyediakan stock suku cadang asli & 2.51 & 3.81 & -1.3 \\
\hline 12 & $\begin{array}{l}\text { Penjelasan petugas bengkel secara langsung pada waktu } \\
\text { penyerahan, tentang perawatan/perbaikan secara } \\
\text { keseluruhan yang telah dilaksanakan }\end{array}$ & 2.68 & 3.85 & -1.17 \\
\hline 13 & $\begin{array}{l}\text { Penjelasan petugas bengkel secara langsung pada waktu } \\
\text { penyerahan, tentang keseluruhan biaya yang akan dibayar }\end{array}$ & 2.95 & 3.78 & -0.83 \\
\hline 14 & $\begin{array}{l}\text { Kewajaran ongkos kerja (dibandingkan dengan mutu } \\
\text { kerjanya) }\end{array}$ & 2.25 & 3.20 & -0.95 \\
\hline 15 & $\begin{array}{l}\text { Kewajaran harga suku cadang asli (dibandingkan dengan } \\
\text { mutunya) }\end{array}$ & 2.28 & 3.83 & -1.55 \\
\hline 16 & Perhatian petugas terhadap kebutuhan/keluhan anda & 2.79 & 3.83 & -1.04 \\
\hline 17 & Keramahan dan kesopanan petugas bengkel/suku cadang & 3.23 & 3.79 & -0.56 \\
\hline 18 & $\begin{array}{l}\text { Petugas bengkel kemudian menghubungi anda untuk } \\
\text { mengetahui apakah Toyota anda sudah dikerjakan dengan } \\
\text { benar dan baik }\end{array}$ & 3.09 & 3.73 & -0.64 \\
\hline 19 & $\begin{array}{l}\text { Pemberitahuan petugas bilamana kendaraan anda telah } \\
\text { diservis/diperbaiki }\end{array}$ & 1.58 & 3.61 & -2.03 \\
\hline 20 & $\begin{array}{l}\text { Penjelasan petugas bengkel tentang perkiraan biaya } \\
\text { perawatan perbaikan }\end{array}$ & 2.30 & 3.80 & -1.5 \\
\hline \multicolumn{4}{|c|}{ Rata-rataGap } & -1.08 \\
\hline \multicolumn{4}{|c|}{ Rata - rata Harapan } & 3.70 \\
\hline
\end{tabular}




\section{Matriks Hubungan (Relationship Matrix) antara Kebutuhan Pelanggan dan Karakteristik Teknis}

Tabel 3. Matrix relationship

\begin{tabular}{|c|c|c|c|c|c|c|c|c|c|c|c|c|c|c|}
\hline $\begin{array}{l}\text { Karakteristik Teknis } \\
\text { Kebutuhan } \\
\text { konsumen }\end{array}$ & 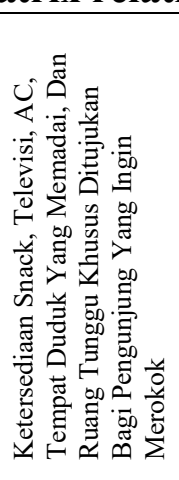 & 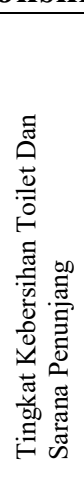 & 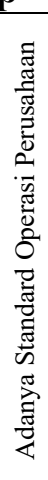 & 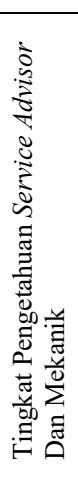 & 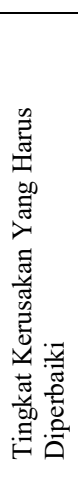 & 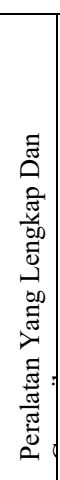 & 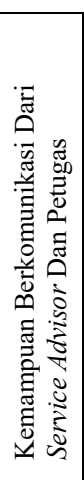 & 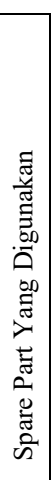 & 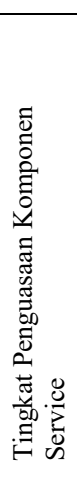 & 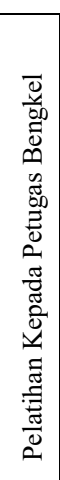 & 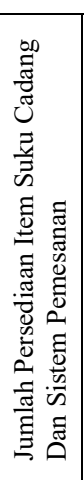 & 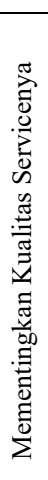 & 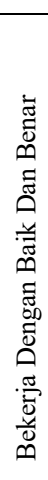 & 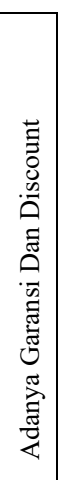 \\
\hline $\begin{array}{l}\text { Fasilitas dan } \\
\text { kebersihan ruang } \\
\text { tunggu }\end{array}$ & 9 & 9 & 3 & & & & & & & & & & & \\
\hline $\begin{array}{l}\text { Sikap petugas } \\
\text { terhadap } \\
\text { perbaikan yang } \\
\text { masih dalam } \\
\text { garansi perbaikan }\end{array}$ & & & 9 & 9 & & & & & & & & & & \\
\hline $\begin{array}{l}\text { Ketepatan janji } \\
\text { petugas mengenai } \\
\text { waktu } \\
\text { penyelesaian } \\
\text { perawatan / } \\
\text { perbaikan } \\
\end{array}$ & & & 3 & 9 & & & 9 & & & & & & & \\
\hline $\begin{array}{l}\text { Kecepatan } \\
\text { penyelesaian } \\
\text { pekerjaan }\end{array}$ & & & & 9 & 9 & 9 & & & & & & & & \\
\hline $\begin{array}{l}\text { Perawatan / } \\
\text { perbaikan yang } \\
\text { tepat sesuai } \\
\text { dengan } \\
\text { permintaan / } \\
\text { keluhan }\end{array}$ & & & & & & 9 & 9 & 3 & 9 & & & 9 & 3 & \\
\hline $\begin{array}{l}\text { Penjelasan } \\
\text { petugas bengkel } \\
\text { tentang perkiraan } \\
\text { biaya perawatan / } \\
\text { perbaikan }\end{array}$ & & & 3 & 3 & 9 & & 9 & 9 & 9 & & & 3 & & \\
\hline Penjelasan & & & 3 & 9 & 3 & & 9 & 3 & 9 & & & 3 & 3 & \\
\hline
\end{tabular}


Suryopratomo, Anggit. 2019. Strategi Pengembangan Kualitas Pelayanan untuk Memenuhi Keinginan Konsumen Pada Bengkel Wijaya Toyota. Ekonam, 1(1): 39-54.

\begin{tabular}{|c|c|c|c|c|c|c|c|c|c|c|c|c|c|c|}
\hline $\begin{array}{l}\text { Karakteristik Teknis } \\
\text { Kebutuhan } \\
\text { konsumen } \\
\text { petugas bengkel } \\
\text { tentang } \\
\text { perawatan / } \\
\text { perbaikan yang } \\
\text { akan dilakukan }\end{array}$ & 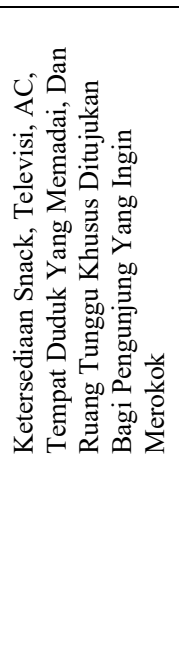 & 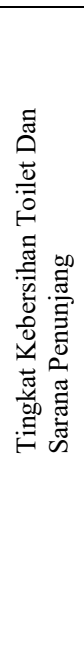 & 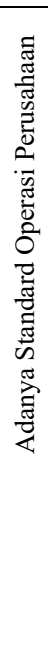 & 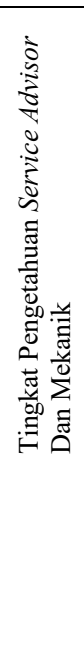 & 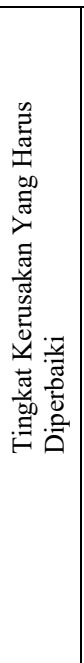 & 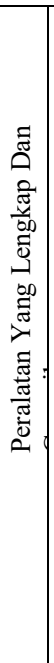 & 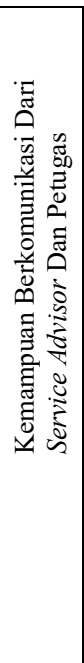 & 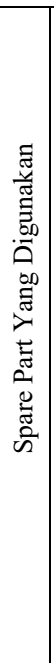 & 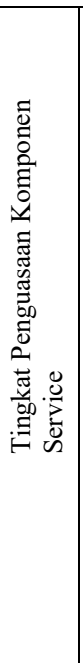 & 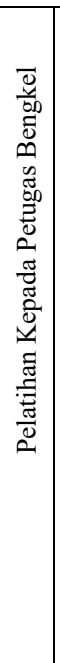 & 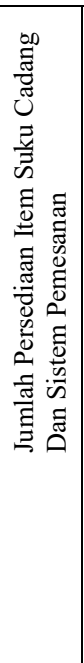 & 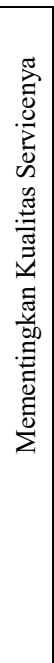 & 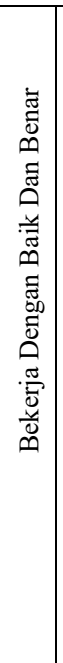 & 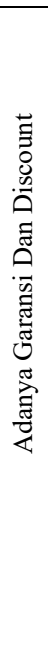 \\
\hline $\begin{array}{l}\text { enyediakan stock } \\
\text { suku cadang asli }\end{array}$ & & & 3 & 3 & & & 9 & 9 & & & 9 & 9 & & 9 \\
\hline $\begin{array}{l}\text { Penjelasan } \\
\text { petugas bengkel } \\
\text { secara langsung } \\
\text { pada waktu } \\
\text { penyerahan, } \\
\text { tentang } \\
\text { perawatan / } \\
\text { perbaikan secara } \\
\text { keseluruhan yang } \\
\text { telah } \\
\text { dilaksanakan }\end{array}$ & & & 3 & 3 & & & 9 & & 3 & 3 & & 9 & 9 & \\
\hline $\begin{array}{l}\text { Penjelasan } \\
\text { petugas bengkel } \\
\text { secara langsung } \\
\text { pada waktu } \\
\text { penyerahan, } \\
\text { tentang } \\
\text { keseluruhan biaya } \\
\text { yang akan anda } \\
\text { bayar }\end{array}$ & & & 3 & 9 & 9 & & 9 & 9 & 3 & & & 9 & 9 & 9 \\
\hline $\begin{array}{l}\text { Kewajaran } \\
\text { harga suku } \\
\text { cadang asli } \\
\text { (dibandingka } \\
\text { n dengan } \\
\text { mutunya) }\end{array}$ & & & 9 & & & & 9 & 9 & 3 & & & 9 & & 9 \\
\hline $\begin{array}{l}\text { Perhatian petugas } \\
\text { terhadap } \\
\text { kebutuhan / } \\
\text { keluhan anda }\end{array}$ & & & 3 & 3 & & & 9 & 3 & 3 & 3 & & 9 & 9 & \\
\hline $\begin{array}{l}\text { Keramahan dan } \\
\text { kesopanan } \\
\text { petugas bengkel / } \\
\text { suku cadang }\end{array}$ & & & 9 & 3 & & & 9 & 3 & & 3 & & 3 & 3 & \\
\hline $\begin{array}{l}\text { Petugas bengkel } \\
\text { kemudian }\end{array}$ & & & 9 & 3 & 3 & & 9 & & & 3 & & 9 & 3 & \\
\hline
\end{tabular}




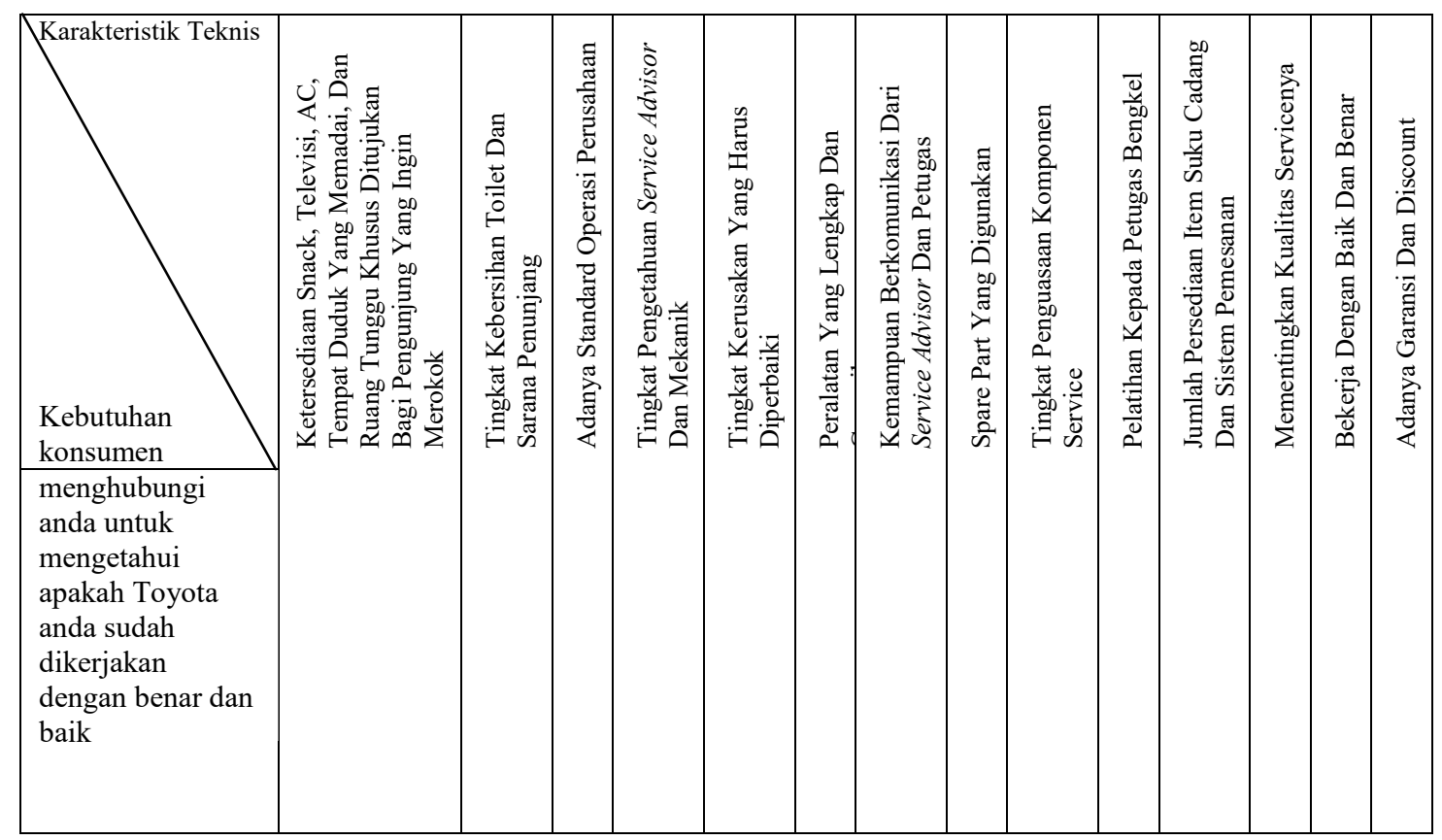

Matriks hubungan dibuat berdasarkan hubungan antara kebutuhan pelanggandengan karakteristik teknis. Dalam perhitungannya diidentifikasi dengan nilai hubungan (relationship value), yaitu:

Nilai 9 : Hubungan yang sangat kuat

Nilai 3 : Hubungan kuat

Nilai 1 : Hubungan lemah

Nilai 0 : Tidak ada hubungan

Pemberian nilai hubungan ini didasarkan atas data kualitatif yang diperoleh antara lain melalui: wawancara dengan pihak perusahaan (kepala bengkel) dan observasi lapangan. Kebutuhan pelanggandiambil 14 atribut dari 20 atribut dikarenakan hanya 14 atribut saja yang memenuhi kriteria yaitu nilai tingkat kepentingan di atas rata-rata keseluruhan yaitu 3,70 sedangkan untuk karakteristik teknis atributnya didapat melalui wawancara dengan pihak perusahaan.

\section{Korelasi Teknis (Technical Corelation)}

Korelasi teknis (Technical Corelation) menunjukkan interaksi antara karakteristik teknik (Technical response). Bentuk korelasi teknis tersebut berupa matriks yang menyerupai atap, sehingga sering disebut Roof Matrix. Korelasi ini penting untuk diidentifikasi agar perusahaan mengetahui karakteristik apa saja yang menjadi prioritas tanpa harus mengabaikan karakteristik teknis lain yang mendukungnya.

Data korelasi ini didapat melalui tanya jawab peneliti dengan Service Advisor yang benar-benar mengerti tentang pelayanan jasa di bengkel Wijaya Toyota. Ukuran tingkat korelasi disimbolkan sebagai berikut:

- $\quad$ : korelasi positif dan kuat

- : korelasi positif

$\Delta \quad$ : korelasi negatif dan kuat

$\Delta \quad$ : korelasi negatif

Kosong : tidak ada korelasi 
Pemberian nilai korelasi teknis ini didasarkan atas data kualitatif yang diperoleh antara lain melalui: wawancara dengan pihak perusahaan dan observasi lapangan.

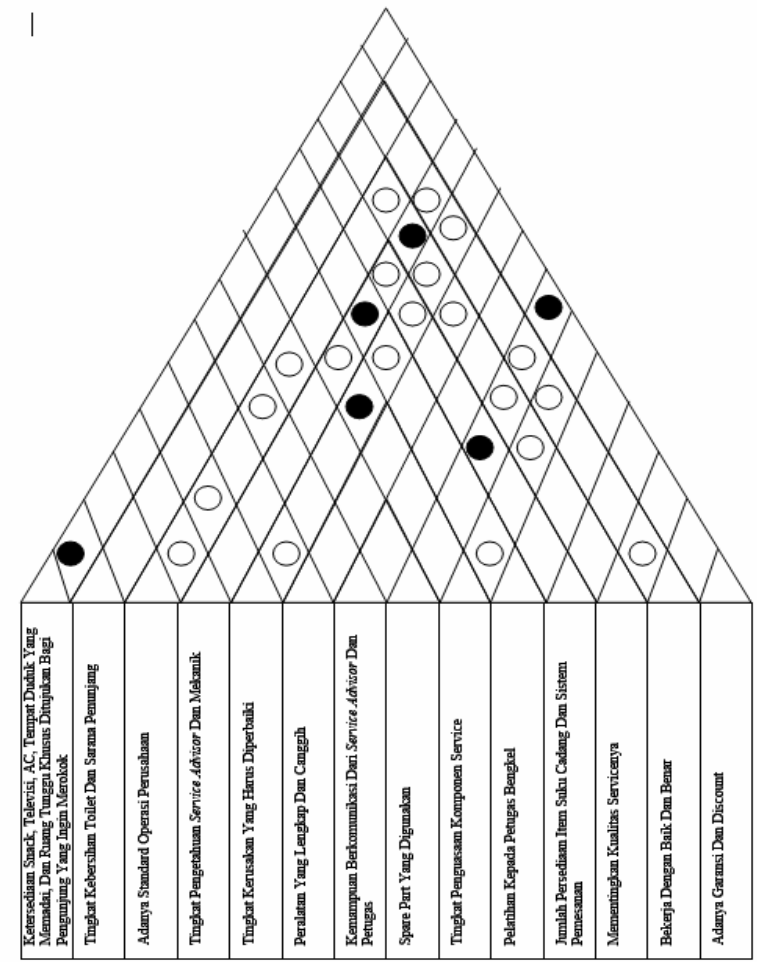

Gambar 1. Korelasi teknis

\section{Strategi-strategi yang dapat dikembangkan}

Strategi-strategi yang dapat dikembangkan untuk komponen kebutuhan pelanggan dengan customer rating $\leq 4$. Hal ini dikarenakan jika nilai customer rating di bawah 4 , berarti atribut tersebut tidak baik bagi pelanggan atas kinerja pelayanan bengkel Wijaya Toyota.

1. Strategi meningkatkan "Kebersihan ruang tunggu dan toilet", hal yang dapat dilakukan diantaranya:

- Kebersihan dan perawatan ruang tunggu dikerjakan oleh bagian kebersihan (cleaning service).

- Menyediakan peralatan kebersihan dengan lengkap.

- Pelatihan kepada petugas yang menjaga ruang tunggu tentang bagaimana cara membersihkan area ruang tunggu dan semua fasilitas yang ada di area ruang tunggu.

2. Strategi meningkatkan "Sikap petugas terhadap perbaikan yang masih dalam garansi perbaikan bengkel", hal yang dapat dilakukan diantaranya:

- Menyediakan informasi terbaru mengenai program-program yang ditawarkan oleh Toyota.

- Informasi yang tersedia lengkap sehingga petugas dan pelanggan tidak mengalami kesalahpahaman.

- Memberikan pelatihan pemahaman kepada petugas Service Advisor dan mekanik tentang standard operasi perusahaan.

3. Strategi meningkatkan "Ketepatan janji petugas mengenai waktu penyelesaian perawatan/perbaikan", hal yang dapat dilakukan di antaranya: 
- Menyediakan informasi bagi pelanggan mengenai pekerjaan yang sedang dikerjakan oleh mekanik.

4. Strategi meningkatkan "Kecepatan penyelesaian pekerjaan", hal yang dapat dilakukan diantaranya:

- Memberikan pelatihan tentang perbaikan masalah-masalah kendaraan Toyota baru.

- Menyediakan e-book tentang kendaraan Toyota.

- Selalu tersedia stock suku cadang.

5. Strategi meningkatkan "Perawatan/perbaikan yang tepat sesuai dengan permintaan/keluhan", hal yang dapat dilakukan diantaranya:

- Pelatihan untuk meningkatkan kemampuan berkomunikasi dari Service Advisor atau petugas.

6. Strategi meningkatkan "Penjelasan petugas bengkel tentang perawatan/perbaikan", hal yang dapat dilakukan diantaranya:

- Pelatihan untuk meningkatkan kemampuan berkomunikasi dari Service Advisor atau petugas mekanik.

7. Strategi meningkatkan "Menyediakan stock suku cadang asli", hal yang dapat dilakukan diantaranya:

- Memperbaiki sistem dokumentasi item dalam persediaan.

8. Strategi meningkatkan "Penjelasan petugas bengkel secara langsung pada waktu penyerahan, tentang perawatan/perbaikan secara keseluruhan yang telah dilaksanakan", hal yang dapat dilakukan diantaranya:

- Pelatihan untuk meningkatkan kemampuan berkomunikasi dari Service Advisor atau petugas mekanik.

9. Strategi meningkatkan "Penjelasan petugas bengkel secara langsung pada waktu penyerahan, tentang keseluruhan biaya yang akan dibayar", hal yang dapat dilakukan diantaranya:

- Pelatihan untuk meningkatkan kemampuan berkomunikasi dari Service Advisor atau petugas mekanik.

10. Strategi meningkatkan "Kewajaran harga suku cadang asli (dibandingkan dengan mutunya)", hal yang dapat dilakukan diantaranya:

- Memberikan garansi atas pembelian suku cadang asli.

- Memberikan discount jasa atas pembelian suku cadang asli.

11. Strategi meningkatkan "Perhatian petugas terhadap kebutuhan/keluhan anda", hal yang dapat dilakukan diantaranya:

- Pelatihan untuk meningkatkan kemampuan berkomunikasi dari Service Advisor atau petugas.

12. Strategi meningkatkan "Keramahan dan kesopanan petugas bengkel/suku cadang", hal yang dapat dilakukan diantaranya:

- Pelatihan untuk meningkatkan kemampuan berkomunikasi dari Service Advisor atau petugas mekanik.

13. Strategi meningkatkan "Petugas bengkel kemudian menghubungi anda untuk mengetahui apakah Toyota anda sudah dikerjakan dengan benar dan baik", hal yang dapat dilakukan diantaranya:

- Pelatihan untuk meningkatkan kemampuan berkomunikasi dari Service Advisor atau petugas. 
14. Strategi meningkatkan "Penjelasan petugas bengkel tentang perkiraan biaya perawatan perbaikan", hal yang dapat dilakukan diantaranya:

- Pelatihan untuk meningkatkan kemampuan berkomunikasi dari Service Advisor atau petugas.

\section{SIMPULAN}

Pertama, layanan yang ingin diutamakan oleh pelanggan bengkel Wijaya Toyota berdasarkan dari nilai kepentingan pelanggan (Voice of Customer) adalah:

1. Penjelasan petugas bengkel secara langsung pada waktu penyerahan, tentang perawatan/perbaikan secara keseluruhan yang telah dilaksanakan.

2. Fasilitas dan kebersihan ruang tunggu.

3. Perawatan/perbaikan yang tepat sesuai dengan permintaan/keluhan.

4. Kewajaran harga suku cadang asli (dibandingkan dengan mutunya).

5. Perhatian petugas terhadap kebutuhan/keluhan anda.

6. Sikap petugas terhadap perbaikan yang masih dalam garansi perbaikan bengkel.

7. Menyediakan stock suku cadang asli.

8. Penjelasan petugas bengkel tentang perkiraan biaya perawatan perbaikan.

9. Keramahan dan kesopanan petugas bengkel/suku cadang.

10. Penjelasan petugas bengkel tentang perawatan/perbaikan.

11. Penjelasan petugas bengkel secara langsung pada waktu penyerahan, tentang keseluruhan biaya yang akan dibayar.

12. Ketepatan janji petugas mengenai waktu penyelesaian perawatan/perbaikan.

13. Kecepatan penyelesaian pekerjaan.

14. Petugas bengkel kemudian menghubungi anda untuk mengetahui apakah Toyota anda sudah dikerjakan dengan benar dan baik.

Kedua, faktor-faktor penentuan karakteristik teknis (Technical Characteristic) mengenai hal-hal yang perlu diperbaiki untuk memenuhi kepentingan pelanggan bagi bengkel Wijaya Toyota adalah:

1. Kemampuan berkomunikasi dari Service Advisor dan mekanik.

2. Mementingkan kualitas servicenya.

3. Tingkat pengetahuan Service Advisor dan mekanik.

4. Adanya standard operasi perusahaan.

5. Suku cadang yang digunakan.

6. Tingkat penguasaan komponen service.

7. Bekerja dengan baik dan benar.

8. Tingkat kerusakan yang harus diperbaiki.

9. Adanya garansi dan discount.

10. Peralatan yang lengkap dan canggih.

11. Pelatihan kepada petugas bengkel.

12. Ketersediaan snack, televisi, AC, tempat duduk yang memadai, dan ruang tunggu khusus ditujukan bagi pengunjung yang ingin merokok.

13. Tingkat kebersihan toilet dan sarana penunjang.

14. Jumlah persediaan item suku cadang dan sistem pemesanan.

Ketiga, faktor strategi-strategi yang bisa dikembangkan agar dapat memenuhi harapan pelanggan adalah: 
1. Kebersihan ruang tunggu dan toilet.

2. Sikap petugas terhadap perbaikan yang masih dalam garansi perbaikan bengkel.

3. Ketepatan janji petugas mengenai waktu penyelesaian perawatan/perbaikan.

4. Kecepatan penyelesaian pekerjaan.

5. Perawatan/perbaikan yang tepat sesuai dengan permintaan/keluhan.

6. Penjelasan petugas bengkel tentang perawatan/perbaikan.

7. Tersedianya stock suku cadang asli.

8. Penjelasan petugas bengkel secara langsung pada waktu penyerahan, tentang perawatan/perbaikan secara keseluruhan yang telah dilaksanakan.

9. Penjelasan petugas bengkel secara langsung pada waktu penyerahan, tentang keseluruhan biaya yang akan dibayar.

10. Kewajaran harga suku cadang asli (dibandingkan dengan mutunya).

11. Perhatian petugas terhadap kebutuhan/keluhan anda.

12. Keramahan dan kesopanan petugas bengkel/suku cadang.

13. Petugas bengkel kemudian menghubungi anda untuk mengetahui apakah Toyota anda sudah dikerjakan dengan benar dan baik.

14. Penjelasan petugas bengkel tentang perkiraan biaya perawatan perbaikan.

\section{DAFTAR PUSTAKA}

Cohen, Lou. 1995. Quality Function Deployment, How to Make QFD Work for You. Massachusetts: Addison-Wesley Publishing Company.

David L. Goetsch. \& Stanley B. Davis. 2010. Quality Management for Organization Excellence. New Jersey: Pearson Education, Inc..

Fitzsimmons. Service Management. New York: McGraw-Hill Company. 2011.

Heizer, J. \& Render, B., 2010. Operations Management, New Jersey: Pearson Education, Inc.

Haksever, Cengiz, Render, barry, Russell, S. Roberta, and Murdick, G. Robert, 2000. Service Management and Operations. Prentice-Hall Inc., Upper Saddler River, New Jersey.

Krawjeski \& Ritzman. 2009. Operation Management. New Jersey: Pearson Education, Inc.

Russel, R. \& Taylor, B. 2010. Operation Management. New York: Pearson Education, Inc.

Swink, Melnyk, Cooper, Hartley. 2011 Managing Operation, Avenue of the Americas, McGraw-Hill Companies Inc.

Sugiyono, Metode Penelitian Bisnis. Bandung: Alfabeta, 2009.

Tjiptono, Fandy. Manajemen Jasa. Edisi Keempat. ANDI, Yogjakarta. 2006. 
Suryopratomo, Anggit. 2019. Strategi Pengembangan Kualitas Pelayanan untuk Memenuhi Keinginan Konsumen Pada Bengkel Wijaya Toyota. Ekonam, 1(1): 39-54. 